\title{
Correlation between stress, stress-coping and current sleep bruxism
}

\author{
Maria Giraki ${ }^{*}$, Christine Schneider ${ }^{2}$, Ralf Schäfer ${ }^{2}$, Preeti Singh ${ }^{1}$, Matthias Franz ${ }^{2}$, Wolfgang HM Raab ${ }^{1}$, \\ Michelle A Ommerborn ${ }^{1}$
}

\begin{abstract}
Background: Stress is discussed as a potential factor in the development of sleep bruxism (SB). The aim of this study was to investigate whether specific stress-factors correlate with SB-activity.

Methods: Sixty-nine subjects, of which 48 were SB-patients, completed three German questionnaires assessing different stress-parameters and stress-coping-strategies: Short questionnaire for recognition of stress-factors (Kurzer Fragebogen zur Erfassung von Belastungen, KFB), Questionnaire for recuperation and strain (Erholungs-BelastungsFragebogen, EBF-24 A/3) and the stress-coping questionnaire (Stressverarbeitungsfragebogen-78, SVF-78). The diagnosis of SB was based on the clinical criteria of the American Academy of Sleep Medicine (AASM). The degree of SB-activity was measured by the Bruxcore-Bruxism-Monitoring-Device (BBMD, Bruxcore, Boston, USA), worn for five consecutive nights and analyzed using a computer-based method. Non-parametric Spearman correlation coefficients, rho, were calculated between the psychometric data and the amount of SB-activity measured by a pixel score of the BBMD.
\end{abstract}

Results: Significant correlations were found for 'daily problems' $(r=0.461, p<0.01)$, 'trouble at work' $(r=0.293)$, 'fatigue' ( $r=0.288)$, 'physical problems' ( $r=0.288)$ and the coping-strategy 'escape' $(r=0.295)(a l l p<0.05)$.

Conclusions: Within the limitations of this study it could be shown that subjects with high SB-activity tend to feel more stressed at work and in their daily life, which in turn might influence their physical state. These subjects also seem to deal with stress in a negative way. However, due to the rather low to almost moderate correlation coefficients and the descriptive character of the study, further investigations are necessary to examine a possible causal relationship.

\section{Background}

Sleep bruxism (SB) is defined as a 'stereotyped movement disorder characterized by grinding or clenching of the teeth during sleep usually associated with sleep arousal' [1]. It might lead to abrasive tooth wear, hypermobility of teeth, tooth hypersensitivity, hypertrophy of the masticatory muscles and pain in the masticatory muscles [2]. There are no gender differences in SB. SB can also be found in children [3,4], but the age distribution reveals a larger incidence in individuals between 20 to 45 years of age $[1,5]$.

Presently, the etiology of SB is not well defined. Different etiological factors have been investigated, e.g.

\footnotetext{
* Correspondence: mgiraki@hotmail.com

'Department of Operative and Preventive Dentistry and Endodontics, Heinrich-Heine-University Düsseldorf, Moorenstr 5, 40225 Düsseldorf, Germany
}

(c) 2010 Giraki et al; licensee BioMed Central Ltd. This is an Open Access article distributed under the terms of the Creative Commons Attribution License (http://creativecommons.org/licenses/by/2.0), which permits unrestricted use, distribution, and reproduction in any medium, provided the original work is properly cited.

occlusal interferences [6,7], transient sleep arousal episodes [8-10], a side imbalance in striatal D2 receptor binding $[11,12]$, personality traits $[5,13-16]$, psychosocial factors [17-19] and psychological stress [17,18,20-22]. At the same time, the multifactorial nature of SB is widely accepted [5,12,23-27].

Several authors have investigated stress as one of the causal agents of SB. In 1975 Rugh and Solberg reported that SB seemed to appear after days which were exhausting and stressful [28]. In an epidemiological study on British, German and Italian population samples, self-reported SB was also positively associated with a highly stressful lifestyle [21]. In another research on 1339 employees of a Finnish broadcasting company, frequent bruxism was significantly associated with severely stressful situations at work. Furthermore, frequent bruxism was significantly positively associated with the 
number of occupational health care and dental visits. It was concluded that bruxism may reveal ongoing stress in normal work life [22]. In a follow-up study of 30-50 year-old employees $(n=211)$ of the Finnish broadcasting company it could be reconfirmed that psychosocial factors and perceived stress should not be ignored [17]. In the same study it could also be shown that smoking was significantly positively associated with frequent bruxism. It was concluded that tobacco use may both amplify the patient's pain response and provoke bruxism [17]. Another epidemiological study examined the relationship between psychosocial job stress and SB in a Japanese population of 1944 male and 736 female factory workers. The study found that SB was weakly associated with some aspects of job stress in men among the Japanese working population [18].

Two further studies demonstrated an association between SB and an overtly ambitious character or behavior (Type A), which in turn is related to a stressful life $[14,15]$. A psychometric study found a significantly higher stress perception in bruxers compared to healthy controls [29]. Studies on urinary catecholamines in bruxers, indicating stressful states, detected a significant association of urinary epinephrine and dopamine with bruxism in children [30], as well as a positive relationship between increased urinary epinephrine and high levels of sleep masseter muscle activity [31]. Animal experiments with rats concerning the relationship between emotional stress and brux-like activity of their masseter muscles have also suggested a positive correlation [32].

Furthermore Schneider et al. investigated stress-coping strategies in patients with SB compared to non-bruxing controls. They observed a significant difference in positive coping strategies, which are capable of reducing stress, between the two groups. SB-patients reported significantly less positive coping strategies, like 'reaction control' and 'positive self-instructions'. Based on the above, a deficit of functional coping strategies in SBpatients could be demonstrated [33].

In contrast to these findings, two other studies showed that there was no relationship between the degree of SB and self-reported stress [34,35]. Another study, found no significant differences between bruxers and controls with respect to perceived stress during the previous year [36].

Overall, the majority of studies suggest an association between stress and SB, although increased SB as a direct consequence of diurnal stress could not be proved. It remains debatable as to which specific stress-factors correlate with SB.

According to the transactional model of stress and coping [37], stress depends on the impact of an external stressor, which is mediated by the appraisal of the stressor (primary appraisal) on the one hand, and the appraisal of the individual's capabilities to handle the situation (secondary appraisal) on the other hand. Coping represents the actual strategy of an individual to deal with the stressor. Dispositional coping styles are generalized ways of behaving in stressful situations, stable across time and circumstances. However, investigations regarding the correlation between stress-coping and $\mathrm{SB}$ are rare.

Therefore, the aim of the present study was to investigate whether specific stress related factors and coping strategies, from different areas of life, correlate with SB. A reliable and concurrently practicable instrument should be used, in order to measure the degree of SB. This allows for a high number of participants to be easily examined.

The literature states numerous methods with different validity and practicability for the assessment of SB-activity: laboratory polysomnographic recordings as the gold standard $[9,10,12,27,38]$, portable electromyographic (EMG) recordings [28,31,39], accelerometer systems [40], a force-based bruxism detection system [41], questionnaires for self-evaluation of bruxism $[14,21,22]$, dental examinations [30,42], examination of stone casts [43] as well as measuring abrasion on a diagnostic plate, the Bruxcore Bruxism-Monitoring Device (BBMD, Bruxcore, USA) [44]. Recently, it has been shown that the BBMD, in combination with a newly computer-based analyzingmethod, is a reliable and feasible instrument to quantify abrasion as an indication for current SB [45].

The hypothesis used in this study was that high levels of specific stress related factors are associated with a high level of SB-activity. Additionally, it was hypothesized that handling stress in a non-effective way may lead to high SB-activity.

\section{Methods \\ Sample}

The sample consisted of 69 subjects, of which 48 were SB-patients. They were all German native speakers and responded to announcements in local newspapers and placards on campus. Subjects were screened following a thorough dental functional analysis [recommendations of the German Society of Dentistry and Oral Medicine (DGZMK)]. The diagnosis of SB was made clinically and was based on the criteria of the American Academy of Sleep Medicine (AASM) [1]. Individuals that met the following criteria were included in the study: healthy adults, aged between 20 to 40 years and sleeping partner reports of grinding sounds during the night in the last 6 months. Additionally, at least one of the following symptoms: self report of muscle fatigue or pain on awakening, abnormal tooth wear or shiny spots on restorations and masseter hypertrophy upon digital palpation. 
Exclusion criteria were: current dental treatment, cognition of SB for more than ten years, severe psychological disorders and/or the use of antipsychotic psychotropic drugs, alcohol-abuse, central nervous system and/or peripheral nervous system disorders, more than two missing molars (excluding third molars), the presence of a prosthesis or extensive prosthetic restorations and the presence of gross malocclusion. Healthy adults, from whom SB could be excluded, represented the nonbruxing subjects. Exclusion criteria were the same as for the SB-patients, as well as any signs and symptoms of SB. SB-patients did not differ from the non-bruxing subjects with respect to age, gender, education and the type of occlusal guidance scheme. The sociodemographic characteristics are displayed in Table 1.

All subjects gave written informed consent to the procedures approved by the Institutional Human Subjects Ethics Committee (Heinrich-Heine-University Duesseldorf).

\section{Design and instruments}

In order to quantify current $\mathrm{SB}$ its degree was measured using the BBMD. The BBMD is a $0.51 \mathrm{~mm}$ thick plate, consisting of four laminated polyvinyl chloride sheets of different colors and a halftone dot screen on the topmost surface (Figure 1 and 2). The BBMD combined with a semi-automatic computer-based analyzing method has been investigated in a previous study and is described as a clinically feasible and reliable instrument with good sensitivity and specificity parameters, which allows quantification of current SB over a short period [45]. The BBMD had to be worn for five consecutive nights in the upper jaw. The computer-based analysis for quantification of abrasion on the BBMD was done analogue to the procedure described by

Table 1 Sociodemographic characteristics and data related to the type of occlusal guidance scheme

\begin{tabular}{|c|c|c|c|}
\hline & $\begin{array}{l}\text { SB-patients } \\
(n=48)\end{array}$ & $\begin{array}{l}\text { Non-bruxing } \\
\text { subjects } \\
(n=21)\end{array}$ & $P$ \\
\hline Age & $29.38( \pm 4.41)$ & $28.10( \pm 5.75)$ & n.s. \\
\hline Gender & $33 \mathrm{~F}, 15 \mathrm{M}$ & $13 \mathrm{~F}, 8 \mathrm{M}$ & n.s..$^{b}$ \\
\hline Education $^{c}$ & $2 x_{1} ; 29 x_{2} ; 17 x_{3}$ & $1 x_{1} ; 16 x_{2} ; 4 x_{3}$ & n.s. \\
\hline $\begin{array}{l}\text { Canine protected } \\
\text { articulation (\%) }\end{array}$ & 2.1 & 9.5 & n.s. \\
\hline $\begin{array}{l}\text { Anterior protected } \\
\text { articulation (\%) }\end{array}$ & 25.0 & 28.6 & n.s. \\
\hline Group function (\%) & 72.9 & 61.9 & n.s. \\
\hline
\end{tabular}

n.s. $=$ not significant; ${ }^{*}=p<0.05 ;{ }^{* *}=p<0.01 ;{ }^{* * *}=p<0.001$

${ }^{a} t$-test; values are presented as mean \pm standard deviation

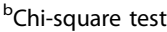

'Education was divided into three grades: $\mathrm{x}_{1}-10 \mathrm{yr}$ of school;

$\mathrm{x}_{2}-13 \mathrm{yr}$ of school; $\mathrm{x}_{3}-18 \mathrm{yr}$ of school (university).

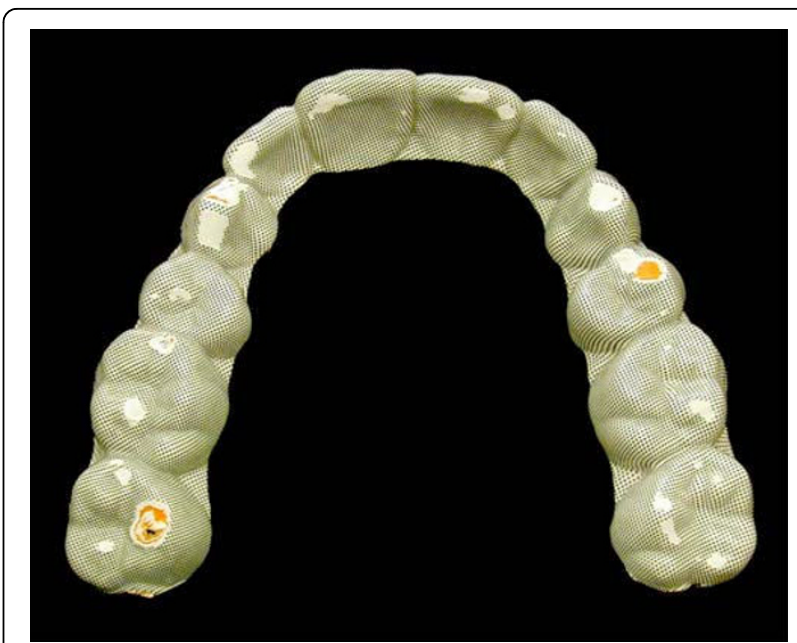

Figure 1 The BBMD, worn by a SB-patient for five consecutive nights, showing all abraded layers of the plate.

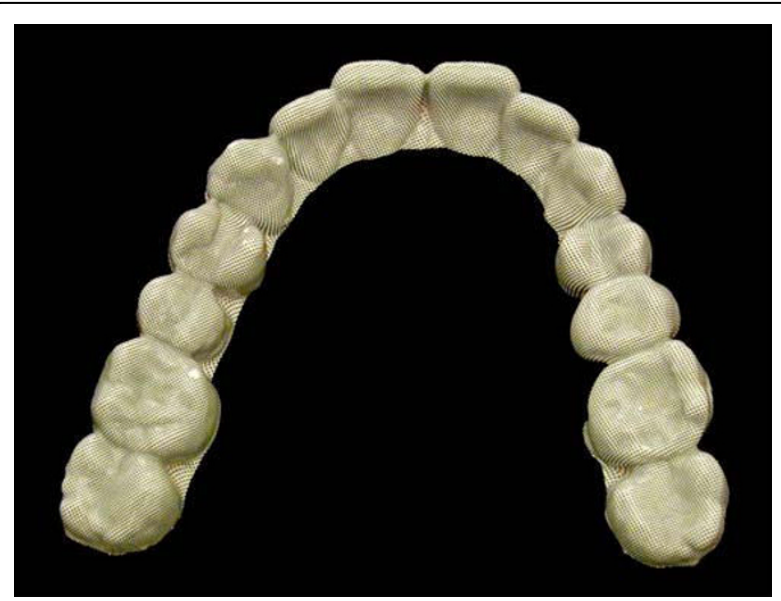

Figure 2 The BBMD, worn by a non-bruxing subject for five consecutive nights.

Ommerborn et al. [45] and lead to a so called pixel score.

For the assessment of current stress, subjects completed the following three established and valid German stress- and coping questionnaires: Short questionnaire for recognition of stress-factors (Kurzer Fragebogen zur Erfassung von Belastungen, KFB) [46], Questionnaire for recuperation and strain (Erholungs-Belastungs-Fragebogen, EBF-24 A/3) [47] and the Stress-coping questionnaire (Stressverarbeitungsfragebogen-78, SVF-78) [48]. Following assessment for exclusion criteria and dental examination but prior to the insertion of the BBMD, participants completed the three questionnaires sitting in a quiet room.

The KFB is the short version of a German questionnaire concerning daily life and stress situations [46]. It 
consists of 16 items, summarized in 4 subscales: 1 . 'partnership' (7 items), 2. 'daily problems' (3 items), 3. 'social contacts' (3 items), 4. 'trouble at work' (3 items). Subjects have to quantify their accordance to the several statements on a six-point scale with a range from ' 0 ' ('it does not apply') to ' 5 ' ('it applies exactly'). Outcomes of the addition of the items form the subscale-values. The total-score of the KFB is calculated by addition of the four subscale-values. The KFB was found to have a satisfying validity [46]. High values for the four subscales imply a high degree of stress in different situations.

The EBF-24 A/3 is the short version of a German questionnaire for the evaluation of a current 'recuperation-strain-balance' [47]. It consists of 24 items, asking for the current balance or imbalance between stressful events and those which help to recuperate. Subjects have to quantify, how often the several events occurred in the last three days with the help of a 7-point response scale. It is suggested that adequate recuperation mechanisms are able to equalize strain. The items are summarized in 12 subscales: 1. 'general strain', 2. 'emotional strain', 3. 'social strain', 4. 'unresolved problems', 5. 'fatigue', 6. 'lack of energy', 7. 'physical problems', 8. 'success', 9. 'social recreation', 10. 'physical relaxation', 11. 'general content', 12. 'sleep'. Subscales 1.-7. are merged to the major scale 'strain' and subscales 8.-12. result in the major scale 'recuperation'. The validity of the questionnaire clearly shows correlations to the current mental state [47]. High values for the scale 'strain' imply a high amount of stressful events, whereas high values for the scale 'recuperation' imply a high level of events that help to recuperate and to equalize strain.

The SVF-78 is the short version of a German coping questionnaire [48]. It consists of 78 items (5-point response scale, 0-4), which survey the different strategies of coping. The basic assumption of the questionnaire is that these strategies are relatively situationinvariant traits, which are thought to be stable over time. The items are summarized in 13 subscales: 1 . 'self-aggrandizement by comparison with others', 2 . 'denial of guilt', 3. 'distraction', 4. 'substitute gratification', 5. 'situation control', 6. 'reaction control', 7. 'positive self-instructions', 8. 'need for social support', 9. 'avoidance', 10. 'escape', 11. 'rumination', 12. 'resignation', 13. 'self-blame'. Subscales 1 . to 8 . are merged to the major scale 'positive coping strategies'. They represent strategies, appropriate to reduce stress. Subscales 9 to 13 result in 'negative coping strategies' which tend to enhance stress. The SVF-78 is the most established and most frequently applied coping-questionnaire in Germany [49]. It is the only well evaluated instrument, investigating general coping styles as a stable trait in German language [50].
Validity of the SVF-78 has been proved by factorial analysis and correlation with divergent and convergent traits [48,51].

High values for positive coping-strategies imply a high degree of strategies that are appropriate to reduce stress, whereas high values for negative coping-strategies imply a high degree of strategies that are prone to augment stress.

\section{Statistical analysis}

The statistical analysis was performed using the statistical software 'SPSS' Version 15.0 (SPSS ${ }^{\circ}$ Software GmbH, Munich). Non-parametric Spearman correlation coefficients, rho, were calculated between the psychometric data and the pixel score of the BBMD for the whole sample of $n=69$ subjects. For the detection of meandifferences between the two groups concerning the sociodemographic characteristics and data related to the type of occlusal guidance scheme t-test and Chi-square test were applied (Table 1).

An $\alpha$-error probability of $\mathrm{p}<0.05$ was adopted as the statistically significant level.

For the interpretation of the correlations' degree, with reference to the value of the correlation coefficient $r$, the classification according to Zöfel was applied [52].

According to this classification a value between 0.2 and 0.5 indicates a low correlation and a value between 0.5 and 0.7 , a moderate correlation.

\section{Results}

\section{Sociodemographic data}

The analysis of the sociodemographic characteristics showed, that the number of female subjects was about two times higher than the number of male subjects. Furthermore SB-patients did not differ significantly from non-bruxing subjects with regards to age, gender and education. In addition, SB-patients and non-bruxing subjects corresponded in terms of occlusal guidance (Table 1).

\section{Psychometric data and pixel score}

Results showed that different subscales of both the stress questionnaires and the coping questionnaire correlate significantly with $\mathrm{SB}$. The most distinct correlation could be seen between the subscale 'daily problems' of the KFB and the pixel score. This demonstrated that the more the problems in daily life, the higher was the degree of SB. For the KFB, it could also be shown, that SB descriptively increased with increasing 'trouble at work', even though the correlation coefficient was lower than for 'daily problems'. In conjunction, these two subscales reveal the significant correlation between the total-score of the KFB and the pixel score. Moreover, significant correlations were found between the pixel 
score and the subscales 'fatigue' and 'physical problems' of the EBF-24 A/3. Both 'fatigue' and 'physical problems' belong to the major scale 'strain'. The more exhausted the subjects were and the more physical problems they had, the more they ground their teeth. All other variables of the KFB and EBF-24 A/3 did not show any significant correlations (Table 2 and Table 3).

Regarding the coping strategies of subjects, the significant correlation found between the pixel score and the subscale 'escape' of the SVF-78 indicated that the more the subjects fled their problems and did not deal with stress in a positive way, the higher was their SB-activity (Table 4).

\section{Discussion}

The present results emphasize the assumption that individuals with high SB-activity seem to feel more stressed in their daily life and at work. This is in accordance with an epidemiological study on British, German, and Italian population samples, where a highly stressful life

Table 2 Spearman correlation coefficient rho and $P$-value for the correlations between the subscales of the KFB and the pixel score of the BBMD $(n=69)$

\begin{tabular}{lll}
\hline Subscale & $\boldsymbol{P}$ & Correlation coefficient \\
\hline Partnership & n. s. & $r=0.075$ \\
Daily problems & $* * *$ & $r=0.461$ \\
Social contacts & n. s. & $r=-0.057$ \\
Trouble at work & $*$ & $r=0.293$ \\
\hline Total Score & $* *$ & $r=0.348$ \\
\hline n.s. = not significant; ${ }^{*}=p<0.05 ;{ }^{* *}=p<0.01 ;{ }^{* *}=p<0.001$ \\
A positive significant correlation between the factors 'daily problems' and \\
'trouble at work' with the pixel score was found.
\end{tabular}

Table 3 Spearman correlation coefficient rho and $P$-value for correlations between the subscales of the EBF-24 A/3 and the pixel score of the BBMD $(n=69)$

\begin{tabular}{lll}
\hline Subscales & $\boldsymbol{P}$ & Correlation coefficient \\
\hline General strains & n. s. & $r=0.022$ \\
Emotional strains & n. s. & $r=-0.052$ \\
Social strains & n. s. & $r=0.107$ \\
Unresolved problems & n. s. & $r=0.110$ \\
Fatigue & $*$ & $r=0.288$ \\
Lack of energy & n. s. & $r=0.127$ \\
Physical problems & $*$ & $r=0.288$ \\
Success & n. s. & $r=-0.087$ \\
Social recreation & n. s. & $r=0.023$ \\
Physical relaxation & n. s. & $r=-0.140$ \\
General content & n. s. & $r=-0.105$ \\
Sleep & n. s. & $r=0.203$ \\
\hline
\end{tabular}

n.s. $=$ not significant; ${ }^{*}=p<0.05 ;{ }^{* *}=p<0.01 ;{ }^{* *}=p<0.001$

Positive significant correlations between the factors 'fatigue' and 'physical problems' and the pixel score were found.
Table 4 Spearman correlation coefficient rho and $\boldsymbol{P}$-value for correlations between the subscales of the SVF-78 and the pixel score of the BBMD $(n=69)$

\begin{tabular}{lll}
\hline Subscales & $\boldsymbol{P}$ & $\begin{array}{l}\text { Correlation } \\
\text { coefficient }\end{array}$ \\
\hline $\begin{array}{l}\text { Self-aggrandisement by comparison with } \\
\text { others }\end{array}$ & n. s. & $r=-0.046$ \\
Denial of guilt & n. s. & $r=0.050$ \\
Distraction & n. s. & $r=0.122$ \\
Substitute gratification & n. s. & $r=0.030$ \\
Situation control & n. s. & $r=0.000$ \\
Reaction control & n. s. & $r=-0.086$ \\
Positive self-instructions & n. s. & $r=-0.219$ \\
Need for social support & n. s. & $r=-0.107$ \\
Avoidance & n. s. & $r=-0.149$ \\
Escape & $*$ & $r=0.295$ \\
Rumination & n. s. & $r=0.072$ \\
Resignation & n. s. & $r=0.077$ \\
Self-blame & n. s. & $r=-0.016$ \\
\hline
\end{tabular}

n.s. $=$ not significant; ${ }^{*}=p<0.05 ;{ }^{* *}=p<0.01 ;{ }^{* * *}=p<0.001$

A positive significant correlation between the factor 'escape' and the pixel score was found.

was positively associated with self-reported SB [21]. Similar results are also provided in a previous study on 1339 employees of a Finnish broadcasting company, which demonstrated that frequent bruxers, regardless of work category, reported more stress. In the same study, frequent bruxism was both significantly positively associated with severe stress experience and with the number of occupational health care and dental visits [22]. In a follow-up study of 30-50 year-old employees $(n=211)$ of the Finnish broadcasting company it could be reconfirmed that psychosocial factors and perceived stress should not be ignored [17]. The assumption of Ehlert, who describes a correlation between stress in daily life ('daily hassle') and the individuals' health status, concerns a similar theory [53]. Similarly, in the present study, it may be assumed that stress could influence the subjects' physical state. This is expressed in the statistically significant values for the subscales ,fatigue' and ,physical problems' of the EBF-24 A/3. In this context the follow-up study mentioned above could play an important role: it could be shown that, among others, smoking was significantly positively associated with frequent bruxism. It was concluded that tobacco use may both amplify the patient's pain response and provoke bruxism [17]. The factor 'smoking' was however, not controlled for in the present study, so that a possible influence cannot be excluded.

In addition, this study revealed that subjects with high pixel scores do not seem to be able to deal with stress in an adequate way. They seem to prefer negative coping strategies like ,escape'. This, in general, increases the 
feeling of stress, instead of looking at the stressor in a positive way. Schneider et al. who investigated maladaptive coping strategies in individuals with SB compared to non-bruxing controls observed less positive coping strategies in SB-patients and could therefore also demonstrate a deficit of functional coping strategies for the SB-patients [33].

Similar findings were seen in patients with craniomandibular dysfunction, which demonstrated that these individuals rather daydream, push problems away and do not instruct themselves positively [54]. Other psychosocial factors like trait anxiety [36] coincide with their ineffective reactions like resignation and flight.

The stress questionnaires used in the present study represent valid instruments for the acquisition of stressparameters of a German population [46-49]. As all subjects were German native speakers, it can be assumed that small semantic differences were also understood.

Due to the fact that all questionnaires were used only for the inquiry of subjective current stress-parameters, meaningful results concerning the correlation between two current parameters - stress and current SB - could be expected. The presence of SB was diagnosed clinically according to the AASM [55] and was done only by one trained dentist, in order to minimize variance. This, however, could be questioned, because clinical criteria like abnormal tooth wear or shiny spots on restorations do not verify the presence of current SB. It could be supposed that the tooth wear had been caused many years ago. Nevertheless, criteria employed in the study, like sleeping partner's report of grinding sounds in combination with the self-report of muscle fatigue or pain on awakening give a clear hint towards current SB-activity. Furthermore, a previous investigation has verified the ability of the BBMD combined with the computerbased analyzing method, used in this investigation, to record current SB-activity [45].

In summary, several stress-parameters described here, concerning specific stress-factors as well as stress-coping strategies correlated significant with SB. Essentially, the stress-factor 'daily problems' seems to play an important role for increasing SB-activity, expressed by a high significance-level and moderate correlation coefficient $r$, according to the scale of Zöfel [52]. Although causal relationships between stress and SB cannot be concluded due to the descriptive character of the statistical analysis, the present results may be interpreted as a promising hint about an existing relationship between stress and SB. However, since, to date, the etiology of SB remains unclear, a moderate correlation between factors like abrasion on a plate, verified as current SB by the computer-based analyzing method, and stress gives enough ground for future investigations in this field in order to identify possible causal relationships between stress, stress-coping and SB.

Concluding from the above, it is worthwhile to further examine stress as one possible etiological factor for the development of SB in experimental trials, preferably in a sleep laboratory. Of interest would be a study designed to measure stress-parameters, stress-reaction and the SB-activity of different subjects, who are exposed to the same stressor, regularly for a longer, defined observation period. Such a study design would allow identification of the different types of daily life events and factors at work that are believed to be stressful. Furthermore, it would be interesting to investigate the reasons due to which individuals in a similar stress situation feel stressed at times and not at others. In order to understand the parameter 'coping' more precisely, further research needs to be carried out into the following: what leads to the development of positive or negative coping strategies?, to what extent does stress influence and modify the type of coping strategies?, and whether positive coping of daily problems reduces SB-activity. In the same context, it should additionally be examined, whether SB itself could lead to stress and/or maladaptive coping strategies as a result of the chronic dental and/or myofascial disturbance and a possible subsequent helplessness felt by the patient.

\section{Conclusions}

Within the limitations of this study it could be shown that subjects with high SB-activity tend to feel more stressed at work and in their daily life, which in turn might influence their physical state. These subjects also seem to deal with stress in a negative way. However, due to the rather low to almost moderate correlation coefficients and the descriptive character of the study, further investigations are necessary to examine a possible causal relationship

\section{Acknowledgements}

The authors thank Dr Andreas Gotter for his assistance with the computerbased analyzing program.

This study has been supported in part by grants from the German Research Foundation (FR 839/6-1 and 6-2).

\section{Author details}

'Department of Operative and Preventive Dentistry and Endodontics, Heinrich-Heine-University Düsseldorf, Moorenstr 5, 40225 Düsseldorf, Germany. ${ }^{2}$ Clinical Institute of Psychosomatic Medicine and Psychotherapy, Heinrich-Heine-University Düsseldorf, Moorenstr 5, 40225 Düsseldorf, Germany.

\section{Authors' contributions}

MAO, CS and RS conceived the study design, MG fabricated the BBMDs, performed its analysis as well as the statistical data analysis and wrote the manuscript. CS conducted the psychological part of this study, MAO executed the dental part of this study, PS made the necessary language correction in the manuscript, MF and WHMR participated in the early 
preparation of the manuscript and contributed to writing the article. All authors have read and approved the final manuscript.

\section{Competing interests}

The authors declare that they have no competing interests.

Received: 7 July 2009

Accepted: 5 March 2010 Published: 5 March 2010

\section{References}

1. AASM: The International Classification of Sleep Disorders, Revised: Diagnostic and coding manual Westchester, IL: American Academy of Sleep Medicine, 22005.

2. Kato T, Dal-Fabbro C, Lavigne GJ: Current knowledge on awake and sleep bruxism: overview. Alpha Omegan 2003, 96:24-32.

3. Feteih RM: Signs and symptoms of temporomandibular disorders and oral parafunctions in urban Saudi Arabian adolescents: a research report. Head Face Med 2006, 2:25

4. Barbosa Tde S, Miyakoda LS, Pocztaruk Rde L, Rocha CP, Gaviao MB: Temporomandibular disorders and bruxism in childhood and adolescence: review of the literature. Int J Pediatr Otorhinolaryngol 2008, 72:299-314.

5. Bader G, Lavigne G: Sleep bruxism; an overview of an oromandibular sleep movement disorder. Sleep Med Rev 2000, 4:27-43.

6. Clark GT, Tsukiyama Y, Baba K, Watanabe T: Sixty-eight years of experimental occlusal interference studies: what have we learned?. J Prosthet Dent 1999, 82:704-713.

7. Ramfjord SP: Bruxism, a clinical and electromyographic study. J Am Dent Assoc 1961, 62:21-44.

8. Kato T, Rompre P, Montplaisir JY, Sessle BJ, Lavigne GJ: Sleep bruxism: an oromotor activity secondary to micro-arousal. J Dent Res 2001, 80:1940-1944

9. Macaluso GM, Guerra P, Di Giovanni G, Boselli M, Parrino L, Terzano MG: Sleep bruxism is a disorder related to periodic arousals during sleep. $J$ Dent Res 1998, 77:565-573.

10. Kato T, Montplaisir JY, Guitard F, Sessle BJ, Lund JP, Lavigne GJ: Evidence that experimentally induced sleep bruxism is a consequence of transient arousal. J Dent Res 2003, 82:284-288.

11. Lavigne GJ, Soucy JP, Lobbezoo F, Manzini C, Blanchet PJ, Montplaisir JY: Double-blind, crossover, placebo-controlled trial of bromocriptine in patients with sleep bruxism. Clin Neuropharmacol 2001, 24:145-149.

12. Lobbezoo F, Soucy JP, Hartman NG, Montplaisir JY, Lavigne GJ: Effects of the D2 receptor agonist bromocriptine on sleep bruxism: report of two single-patient clinical trials. J Dent Res 1997, 76:1610-1614.

13. Molina OF, dos Santos J Jr: Hostility in TMD/bruxism patients and controls: a clinical comparison study and preliminary results. Cranio 2002, 20:282-288.

14. Hicks RA, Chancellor C: Nocturnal bruxism and type A-B behavior in college students. Psychol Rep 1987, 60:1211-1214.

15. Pingitore $G$, Chrobak V, Petrie J: The social and psychologic factors of bruxism. J Prosthet Dent 1991, 65:443-446.

16. Kampe T, Edman G, Bader G, Tagdae T, Karlsson S: Personality traits in a group of subjects with long-standing bruxing behaviour. J Oral Rehabil 1997, 24:588-593.

17. Ahlberg J, Savolainen A, Rantala M, Lindholm H, Kononen M: Reported bruxism and biopsychosocial symptoms: a longitudinal study. Community Dent Oral Epidemiol 2004, 32:307-311.

18. Nakata A, Takahashi M, Ikeda T, Hojou M, Araki S: Perceived psychosocial job stress and sleep bruxism among male and female workers. Community Dent Oral Epidemiol 2008, 36:201-209.

19. Manfredini D, Lobbezoo F: Role of psychosocial factors in the etiology of bruxism. J Orofac Pain 2009, 23:153-166.

20. Rugh JD, Harlan J: Nocturnal bruxism and temporomandibular disorders. Adv Neurol 1988, 49:329-341.

21. Ohayon MM, Li KK, Guilleminault C: Risk factors for sleep bruxism in the general population. Chest 2001, 119:53-61.

22. Ahlberg J, Rantala M, Savolainen A, Suvinen T, Nissinen M, Sarna S, Lindholm H, Kononen M: Reported bruxism and stress experience. Community Dent Oral Epidemiol 2002, 30:405-408.
23. Mealiea W, McGlynn F: Temporomandibular disorders and bruxism. Biofeedback: Studies in clinical efficacy New York: PlenumHatch J, Fisher J, Rugh J 1986, 123-151.

24. Lobbezoo F, Naeije M: Bruxism is mainly regulated centrally, not peripherally. J Oral Rehabil 2001, 28:1085-1091.

25. Lavigne GJ, Manzine C: Bruxism. Principles and practice of sleep medicine Philadelphia, PA: WB SaundersKryger MH, Roth T, Dement WC , 3 2000, 773-785.

26. Attanasio R: An overview of bruxism and its management. Dent Clin North Am 1997, 41:229-241.

27. Lobbezoo F, Lavigne GJ, Tanguay R, Montplaisir JY: The effect of catecholamine precursor L-dopa on sleep bruxism: a controlled clinical trial. Mov Disord 1997, 12:73-78.

28. Rugh JD, Solberg WK: Electromyographic studies of bruxist behavior before and during treatment. J Calif Dent Assoc 1975, 3:56-59.

29. Manfredini D, Landi N, Romagnoli M, Bosco M: Psychic and occlusal factors in bruxers. Aust Dent J 2004, 49:84-89.

30. Vanderas AP, Menenakou M, Kouimtzis T, Papagiannoulis L: Urinary catecholamine levels and bruxism in children. J Oral Rehabil 1999, 26:103-110.

31. Clark GT, Rugh JD, Handelman SL: Nocturnal masseter muscle activity and urinary catecholamine levels in bruxers. J Dent Res 1980, 59:1571-1576.

32. Rosales VP, Ikeda K, Hizaki K, Naruo T, Nozoe S, Ito G: Emotional stress and brux-like activity of the masseter muscle in rats. Eur J Orthod 2002, 24:107-117.

33. Schneider C, Schaefer R, Ommerborn MA, Giraki M, Goertz A, Raab WH, Franz M: Maladaptive coping strategies in patients with bruxism compared to non-bruxing controls. Int J Behav Med 2007, 14:257-261.

34. Pierce CJ, Chrisman K, Bennett ME, Close JM: Stress, anticipatory stress, and psychologic measures related to sleep bruxism. J Orofac Pain 1995, 9:51-56.

35. Watanabe T, Ichikawa K, Clark GT: Bruxism levels and daily behaviors: 3 weeks of measurement and correlation. J Orofac Pain 2003, 17:65-73.

36. da Silva AM, Oakley DA, Hemmings KW, Newman HN, Watkins S: Psychosocial factors and tooth wear with a significant component of attrition. Eur J Prosthodont Restor Dent 1997, 5:51-55.

37. Lazarus RS, Folkman S: Stress, appraisal and coping New York: Springer 1984.

38. Lavigne GJ, Rompre PH, Montplaisir JY: Sleep bruxism: validity of clinical research diagnostic criteria in a controlled polysomnographic study. $J$ Dent Res 1996, 75:546-552.

39. Ikeda T, Nishigawa K, Kondo K, Takeuchi H, Clark GT: Criteria for the detection of sleep-associated bruxism in humans. J Orofac Pain 1996, 10:270-282.

40. Yoshimi H, Sasaguri K, Tamaki K, Sato S: Identification of the occurrence and pattern of masseter muscle activities during sleep using EMG and accelerometer systems. Head Face Med 2009, 5:7.

41. Baba K, Clark GT, Watanabe T, Ohyama T: Bruxism force detection by a piezoelectric film-based recording device in sleeping humans. J Orofac Pain 2003, 17:58-64.

42. Carlsson GE, Egermark I, Magnusson T: Predictors of bruxism, other oral parafunctions, and tooth wear over a 20 -year follow-up period. $J$ Orofac Pain 2003, 17:50-57.

43. Marbach JJ, Raphael KG, Janal MN, Hirschkorn-Roth R: Reliability of clinician judgements of bruxism. J Oral Rehabil 2003, 30:113-118.

44. Heller RF, Forgione AG: An evaluation of bruxism control: massed negative practice and automated relaxation training. J Dent Res 1975, 54:1120-1123.

45. Ommerborn MA, Giraki M, Schneider C, Schäfer R, Gotter A, Franz M Raab WH: A new analyzing method for quantification of abrasion on the Bruxcore device for sleep bruxism diagnosis. J Orofac Pain 2005, 19:232-238.

46. Flor H: Psychobiologie des Schmerzes Bern: Huber 1991.

47. Kallus K: Der Erholungs-Belastungs-Fragebogen (EBF) Frankfurt: Swets \& Zeitlinger 1995.

48. Janke W, Erdmann G, Kallus W, Boucsein W: Stressverarbeitungsfragebogen mit SVF 120 und SVF 78 Göttingen: Hogrefe, 32002.

49. Weyers $P$, Ising $M$, Reuter $M$, Janke $W$ : Comparing two approaches for the assessment of Coping. Part I. Psychometric properties and intercorrelations. Journal of Individual Differences 2005, 26:207-212. 
50. Ising $M$, Weyers $P$, Reuter $M$, Janke W: Comparing two approaches for the assessment of coping Part II. Differences in stability in time. Journal of Individual Differences 2006, 27:15-19.

51. Ising M, Weyers $\mathrm{P}$, Janke W, Erdmann G: The psychometric properties of the SVF78 by Janke and Erdmann, a short version of the SVF120. PsyJournals 2001, 22:279-289.

52. Zöfel P: Statistik verstehen München: Addison-Wesley 2002.

53. Ehlert U: Verhaltensmedizin Berlin: Springer Verlag 2003.

54. de Leeuw JR, Steenks MH, Ros WJ, Bosman F, Winnubst JA, Scholte AM: Psychosocial aspects of craniomandibular dysfunction. An assessment of clinical and community findings. J Oral Rehabil 1994, 21:127-143.

55. AASM: The International Classification of Sleep Disorders, Revised:Diagnostic and coding manual Rochester, MN: American Academy of Sleep Medicine 2001.

doi:10.1186/1746-160X-6-2

Cite this article as: Giraki et al:: Correlation between stress, stress-coping and current sleep bruxism. Head \& Face Medicine 2010 6:2.

\section{Submit your next manuscript to BioMed Central} and take full advantage of:

- Convenient online submission

- Thorough peer review

- No space constraints or color figure charges

- Immediate publication on acceptance

- Inclusion in PubMed, CAS, Scopus and Google Scholar

- Research which is freely available for redistribution

Submit your manuscript at www.biomedcentral.com/submit 